\title{
A PRODUÇÃO DO PROFESSOR NA FORMAÇÃO CONTINUADA DO PNAIC: ressonâncias da racionalidade neoliberal
}

\author{
PATRÍCIA LUCIENE DE ALBUQUERQUE BRAGAMONTE
}

Mestre em Políticas Públicas e Gestão Educacional da Universidade Federal de Santa Maria. Pesquisadora do GEPE - Grupo de Estudo e Pesquisa em Educação Especial e Inclusão da UFSM. E-mail: patriciabragamonte@gmail.com

\section{LEANDRA BÔER POSSA}

Professora Doutora do Departamento de Educação Especial, do Programa de Pós-Graduação em Educação e do Programa de Pós-Graduação em Políticas Públicas e Gestão Educacional, UFSM. Coordenadora do GEPE - Grupo de Estudo e Pesquisa em Educação Especial e Inclusão da UFSM. ORCID: https://orcid.org/0000-0001- 6833-7572 E-mail: leandrabp@gmail.com 


\section{Resumo}

O presente texto faz parte da Dissertação intitulada Rastros e vestígios das práticas de produção do professor alfabetizador: uma história a ser considerada na formação continuada, apresentada no Programa de Pós-Graduação em Políticas Públicas e Gestão Educacional, da Universidade Federal de Santa Maria, que objetivou implicar a formação continuada a uma análise das práticas de produção do professor alfabetizador no Brasil. A partir dos Estudos Foucaultianos em Educação, em especial da ferramenta governamentalidade, entendeu-se a produção do professor alfabetizador na formação continuada do PNAIC, no contexto da racionalidade neoliberal.

Palavras-chave: Professor alfabetizador. Governamentalidade. Formação Continuada. PNAIC.

\section{LA PRODUCCIÓN DEL PROFESOR EN LA FORMACIÓN CONTINUADA DEL PNAIC: resonancia de la racionalidad neoliberal}

El presente texto forma parte de la Disertación titulada "Rastros y vestigios de las prácticas de producción del profesor alfabetizador: una historia a ser considerada en la formación continuada", presentada en el Programa de Postgrado en Políticas Públicas y Gestión Educativa, de la Universidad Federal de Santa María , que objetivó implicar la formación continuada a un análisis de las prácticas de producción del profesor alfabetizador en Brasil. A partir de los Estudios Foucaultianos en Educación, en especial de la herramienta gubernamentalidad, se entendió la producción del profesor alfabetizador en la formación continuada del PNAIC, en el contexto de la racionalidad neoliberal.

Palabras clave: Profesor alfabetizador. Gubernamentalidad. Formación continua. PNAIC.

\section{THE PRODUCTION OF THE TEACHER IN THE CONTINUED TRAINING OF THE PNAIC: resonances of neoliberal rationality}

The present text is part of the Dissertation entitled "Traces and traces of the production practices of the literacy teacher: a history to be considered in continuing education", presented in the Graduate Program in Public Policies and Educational Management, Federal University of Santa Maria, which aimed to imply the continuous formation to an analysis of the production practices of the literacy teacher in Brazil. From the Foucaultian Studies in Education, especially the governmentality it was understood the production of the literacy teacher in the continued formation of the PNAIC, within the context of neoliberal rationality.

Key words: Literacy teacher. Governmentality. Continuing Education. PNAIC. 


\section{A PRODUÇÃO DO PROFESSOR NA FORMAÇÃO CONTINUADA DO PNAIC: ressonâncias da racionalidade neoliberal}

Este texto resulta da Dissertação intitulada Rastros e vestígios das práticas de produção do professor alfabetizador: uma história a ser considerada na formação continuada, apresentada no Programa de Pós-Graduação em Políticas Públicas e Gestão Educacional, na Linha de Pesquisa Gestão Pedagógicas e Contextos Educativos, da Universidade Federal de Santa Maria (UFSM), com o objetivo de implicar a formação continuada a uma análise das práticas de produção do professor alfabetizador no Brasil.

A materialidade de pesquisa em questão contemplou diferentes documentos desde a década de 80: Anais dos seminários de alfabetização; Leis e resoluções que regulamentaram o Ciclo Básico de Alfabetização; Revista Nova Escola; Parâmetros Curriculares Nacionais; Referenciais para a Formação de Professores; os programas de formação continuada do professor alfabetizador - Parâmetros Curriculares em Ação, Programa de Formação de Professores Alfabetizadores, Pró-Letramento e Pacto Nacional pela Alfabetização na Idade Certa.

A proliferação de discursos que, além de dizerem quais são os conhecimentos e valores válidos, também ensinam ao professor que alfabetiza como planejar suas aulas, como organizar a sala de aula, como agir em determinadas situações e como trabalhar com seus alunos, torna produtivo pensar nas práticas da produção do professor alfabetizador - tema desta pesquisa. Esses discursos, ao dizer o que as coisas são, vão produzir uma verdade sobre a docência em alfabetização que ao ser "apanhada, memorizada, progressivamente colocada em aplicação [faz dessa verdade] um quase sujeito que reina soberanamente em nós (FOUCAULT, 1997, p. 159$166)$.

Para este texto, interessa-nos analisar algumas práticas do Programa Pacto Nacional pela Alfabetização na Idade Certa (PNAIC) como estratégias de produção do professor alfabetizador no contexto da racionalidade neoliberal. A análise e a discussão dos dados dessa pesquisa concluída e, especificamente, daqueles que servem de materialidade neste trabalho, também derivam dos estudos no Grupo de Estudo e Pesquisa em Educação Especial e Inclusão (GEPE).

A partir dos Estudos Foucaultianos em Educação, em especial da ferramenta governamentalidade, entendeu-se a produção do professor alfabetizador na formação continuada do PNAIC, no contexto da racionalidade neoliberal.

P/Ulail $S$ Salvador, v.3, n.1, p. 135- 154, jan./abr. 2018 


\section{Desenvolvimento}

As práticas dos professores que alfabetizam vêm sendo narradas e construídas em diferentes discursos e momentos históricos, políticos e econômicos. É possível perceber que estão engendrados nessa teia de relações, os debates em torno da educação em consonância com

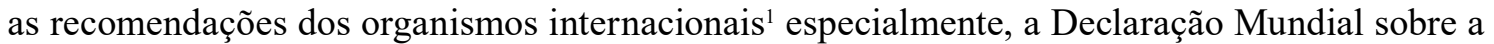
Educação para Todos (UNESCO, 1990) onde a alfabetização é entendida não só

(...) como domínio de instrumentos essenciais para a aprendizagem (como a leitura e a escrita, a expressão oral, o cálculo, a solução de problemas), quanto os conteúdos básicos da aprendizagem (como conhecimentos, habilidades, valores e atitudes), necessários para que os seres humanos possam sobreviver, desenvolver plenamente suas potencialidades, viver e trabalhar com dignidade, participar plenamente do desenvolvimento, melhorar a qualidade de vida, tomar decisões fundamentadas e continuar aprendendo. (UNESCO, 1990, p. 03)

Para efetivar essa nova "concepção de alfabetização", a própria Declaração vai apontar a melhoria urgente "das condições de trabalho e da situação social do pessoal docente [como] elementos decisivos" (UNESCO, 1990, p. 6). Também a Declaração de Dakar (UNESCO, 2001) além de reiterar o compromisso dos governos na garantia de uma educação que satisfaça as necessidades básicas de aprendizagem de todas as crianças, jovens e adultos, reafirmando a visão de uma década atrás, vai intensificar esses discursos, elegendo o investimento educacional na escola primária - alfabetização - de qualidade, como uma das prioridades, "devido à sua importância para todo o desempenho escolar subsequente" (Idem, idem, p. 05).

Dessa maneira, uma das estratégias elencadas para a objetivar a (re)definição da função dos processos de alfabetização foi a inscrição da formação docente, especialmente a continuada, na melhoria da qualidade da educação brasileira a fim de "assegurar à população o acesso pleno a cidadania e uma inserção nas atividades produtivas que permita a constante elevação do nível de vida [como] um compromisso da Nação" (BRASIL, 1999a, p. 39). É o que sinaliza também o relatório Jacques Delors ao afirmar que "a qualidade do ensino é determinada tanto ou mais pela formação contínua dos professores do que pela sua formação inicial” (DELORS, 2001, p. 160).

1 Dentre os organismos internacionais destacam-se o Banco Mundial (BM), o Banco Interamericano de Desenvolvimento (BID), a Organização para as Nações Unidas para a Educação, a Ciência e a Cultura (UNESCO), o Fundo das Nações Unidas para a Infância (UNICEF)e a Comissão Econômica para a América Latina e Caribe (CEPAL). 
Por meio das ações governamentais para resolver os problemas de alfabetização de crianças, percebe-se que os professores são alvos de governo das condutas: são regulados, constituídos e posicionados pelos processos de formação e pelos modos de se conduzir nas práticas que dizem como e porque alfabetizar crianças. Nesse sentido, a formação continuada dos professores alfabetizadores vai operar como um dos instrumentos - como estratégia tática - de que o governo vai dispor para atingir esses determinados fins.

O Governo Federal formulou e implementou, no período de 1995 a 2002, política de formação continuada, focalizada nas séries iniciais do Ensino Fundamental. No período compreendido entre os anos de 1995 e 1998, o MEC priorizará esse segmento, mediante a elaboração de diretrizes, parâmetros curriculares e referencial de formação de professores. No segundo período do governo (1999 a 2002), a política focalizou a formação de professores, procurando influenciar os currículos de formação inicial, bem como a formação continuada. (BRASIL, 2006, p. 12)

Com a implementação dos Parâmetros Curriculares Nacionais (BRASIL, 1997a; 1997b) e dos Referenciais para a Formação de Professores (BRASIL, 1999a), a formação continuada dos professores, em especial dos professores que alfabetizam, constituiu-se uma das áreas estratégicas para reformas educacionais do país que deveriam adequar as "políticas sociais [...] ao cenário de reformulação política e econômica do sistema” (BRASIL, 2006, p. 11). Assim, foram introduzidas novas concepções quanto à identidade do professor e sua formação, privilegiando como base curricular o modelo de competências profissionais para a "construção de uma prática docente qualificada e de afirmação da identidade, da profissionalidade e da profissionalização do professor" (Idem, idem, p. 11).

Desde a década de 90 houve uma intensa mobilização na criação de políticas para a efetivação das novas Diretrizes de Alfabetização e para a superação das metas estabelecidas pelos organismos internacionais. Com isso, muitos programas de formação continuada para professores alfabetizadores foram lançados, reformulados e extintos: Parâmetros Curriculares em Ação (1999b), Programa de Formação de Professores Alfabetizadores (2001), Pró-Letramento (2005) e Pacto Nacional pela Alfabetização na Idade Certa (2012).

Dentre esses Programas, o Pacto Nacional pela Alfabetização na Idade Certa (PNAIC ou Pacto) ainda está em andamento. O PNAIC é um compromisso formal firmado entre os governos do Distrito Federal, dos estados e municípios, de assegurar que todas as crianças estejam alfabetizadas até os oito anos de idade, ao final do $3^{\circ}$ ano do ensino fundamental. Ele foi 
instituído pela Portaria $n^{\circ} 867$, de 4 de julho de 2012 e está sendo desenvolvido através de um programa de formação continuada dos professores que atuam nas turmas de $1^{\circ}, 2^{\circ}$ e $3^{\circ}$ anos do Ensino Fundamental, inclusive em turmas multisseriadas.

As ações do PNAIC são um conjunto integrado de programas, materiais e referências curriculares e pedagógicas, por meio do qual, o Ministério de Educação (MEC), em parceria com as Instituições de Educação Superior (IES), apóia os sistemas públicos de ensino dos Estados, Distrito Federal e Municípios, na alfabetização e no letramento dos estudantes até o final do $3^{\circ}$ ano do ensino fundamental, em escolas rurais e urbanas.

Estas ações apóiam em quatro eixos de atuação: a formação continuada de professores alfabetizadores; os materiais didáticos, literatura e tecnologias educacionais; a avaliação; e a gestão, controle e mobilização social. O principal eixo é a formação continuada de professores alfabetizadores que se caracteriza pela pulverização da formação para todas as escolas das redes de ensino participantes das ações do Pacto, e pela formação e constituição de uma rede de professores orientadores de estudo.

$\mathrm{Na}$ análise da formação continuada do PNAIC foi possível entender que as práticas desenvolvidas nesse programa têm um mapa, um arranjo, que estão conectados com o momento social, político e econômico atual. Nesse sentido, a noção de governamentalidade nos possibilitou pensar que as práticas e os procedimentos desse programa de formação continuada são orientados por uma racionalidade específica de nosso tempo que organiza determinadas formas de conduzir as condutas dos docentes, das crianças e dos demais sujeitos envolvidos com a alfabetização, na produção do professor alfabetizador. O professor alfabetizador é produzido e regulado por uma determinada forma de compreender a ação de governar, por uma determinada racionalidade política, nesse caso, a neoliberal.

Para o empreendimento que foi feito na pesquisa, a partir dos Estudos Foucaultianos, entende-se a racionalidade como "uma forma de ser do pensamento político, econômico e social que organiza as práticas de governo desenvolvidas em nosso presente para governar sujeitos" (LOCKMANN, 2013, p. 58). Em relação ao neoliberalismo, compreende-se como uma

mentalidade de governo, uma concepção sobre como as autoridades devem usar seus poderes para melhorar o bem-estar nacional, sobre os fins que devem buscar, os males que eles devem evitar, os meios que devem usar e, em especial, a natureza das pessoas sobre as quais elas devem agir. (ROSE, 2011, p. 214) 
$\mathrm{Na}$ esteira desse pensamento, formar docentes dentro dos preceitos da racionalidade vigente e despertar suas vontades para continuar aprendendo e investindo em si - para que possam ter cada vez mais recursos para permanecerem no jogo - se torna fundamental, pois, o professor pode ser visto como aquele que, sendo capaz de aceitar as verdades de uma educação, nomeadas como salvadoras, trabalha em prol delas e divulga seus benefícios (MACHADO, 2016). Por isso,

[...] se tomamos governo enquanto condução da conduta, conforme expresso por Foucault no célebre texto O sujeito e o poder (Foucault, 1995a), desde sempre educar é governar, e ao professor que educa cabe apropriar-se de um determinado conjunto de saberes e práticas que, entre outros aspectos, medeiam a relação que cada um estabelece consigo mesmo (self-government) de modo a direcionar sua própria conduta como docente [...]. (COUTINHO, SOMMER, 2011, p. 98)

Juntamente com Coutinho e Sommer (2011), acreditamos que a produção do professor alfabetizador também esteja relacionada ao movimento de intensificação da educação como arte de governar e, nesse sentido, a formação continuada do PNAIC "se estrutura como uma relação de poder [...] da ordem do governo, da condução de condutas [que] qualifica a conduzir outras condutas" (COUTINHO; SOMMER, 2011, p. 98).

A partir do entendimento de que governar é conduzir condutas - à maneira pela qual "conduzimos a nós mesmos, como nos deixamos conduzir e como somos conduzidos, enfim, como nos comportamos sob o efeito de uma conduta" (FOUCAULT, 2008, p. 90) - entendemos a formação continuada do PNAIC como estratégia de governamento docente, no contexto da racionalidade neoliberal, através da qual as autoridades "têm buscado moldar, normalizar e instrumentalizar a conduta, o pensamento, as decisões e aspirações [dos professores] a fim de alcançar os objetivos que elas considerem desejáveis" (MILLER e ROSE 1993, p. 82). Algumas práticas dessa formação conduzem as condutas dos professores para que sejam produzidos e se produzam como professor alfabetizador, assumindo prerrogativas que os incluem nas relações da economia de governo e assim, possam conduzir as condutas das crianças e dos demais sujeitos envolvidos com a alfabetização.

A partir da noção de governamentalidade foi possível perceber algumas táticas de governamento dos docentes na produção de uma subjetividade docente na alfabetização professor alfabetizador - desenvolvidas na formação continuada do PNAIC, a partir disposição de metas, da organização de planilhas de acompanhamento, das estatísticas das avaliações de larga escala e de premiações. 


\section{Metodologia}

Ao escolher seguir as rotas de autores que se aproximam do pensamento de Foucault, este trabalho afastou-se da ideia de método de pesquisa nos sentidos constituídos na Modernidade ${ }^{2} \mathrm{e}$ assumiu que "o método não é o caminho seguro [...] até porque nada mais é seguro, previsível: nem os pontos de saída, nem o percurso, nem os pontos de chegada" (VEIGA-NETO, 1996, p.184). Afastando-se da noção de método como caminho seguro, foi possível pensar nas teorizações como uma caixa de ferramentas que como instrumentos, orientam a investigação e fazem da crítica um martelo ${ }^{3}$.

A partir dos Estudos Foucaultianos em Educação, em especial da ferramenta governamentalidade, a organização da materialidade contemplou diferentes documentos desde a década de 1980: anais dos seminários de alfabetização; leis e resoluções que regulamentaram o Ciclo Básico de Alfabetização; Revista Nova Escola; Parâmetros Curriculares Nacionais; Referenciais para a Formação de Professores; os programas de formação continuada do professor alfabetizador - Parâmetros Curriculares em Ação, Programa de Formação de Professores Alfabetizadores, Pró-Letramento e Pacto Nacional pela Alfabetização na Idade Certa.

Embora possa parecer, em um primeiro momento, que não há ligação entre esses materiais, foi justamente essa característica que permitiu ver, em diferentes pontos, os enredos e o processo das práticas, sem passar por uma reconstrução histórica linear e, assim, ser possível entender como essas práticas foram postas em circulação e se disseminaram, legitimando-se como verdades deste tempo, na produção do professor alfabetizador.

Na medida em que se buscou olhar para os discursos enquanto práticas que constituem o professor alfabetizador, esses materiais não mais foram tomados como documentos, mas como monumentos, já que

[...] em nossos dias, a história é o que transforma os documentos em monumentos e que desdobra, onde se decifravam rastros deixados pelos homens, onde se tentava reconhecer em profundidade o que tinham sido, uma massa de elementos que devem ser isolados, agrupados, tornados pertinentes, inter-relacionados, organizados em conjuntos [...] (FOUCAULT, 1995, p.8)

2 Refere-se à prática moderna da pesquisa em que encaixamos o tema escolhido em uma boa fórmula teórica, já previamente testada e comprovada pela Literatura, aplicando mecanicamente o arsenal teórico ao objeto para iluminar a realidade (BUJES, 2007).

3 A Filosofia do Martelo pode ser melhor entendida a partir de Nietzsche, no livro Crepúsculo dos ídolos (1988). 
Foi assim que se percebeu que esses discursos, através dos movimentos de mobilização e regulação, colocaram em circulação uma série de práticas que, capturadas por uma estrutura legal, instauraram um processo de universalização de determinadas práticas e de produção de um tipo específico de professor.

Essas práticas são disseminadas pelos Programas de formação continuada que, como territórios de confinamento, possibilitam algumas estratégias para moldar e modelar as formas como os professores concebem a si mesmos, as crianças e a docência na alfabetização.

Por isso, olhou-se para a formação continuada do Programa do Governo Federal Pacto Nacional pela Alfabetização na Idade Certa a fim de perceber algumas práticas que eram postas em circulação para a produção do professor alfabetizador. Para esse empreendimento, foi selecionado o Manual do Pacto (BRASIL, 2012d) que sintetiza os objetivos, as ações, a organização e o funcionamento do Programa.

\section{Resultados e discussões}

Ao olharmos para as práticas da formação continuada do PNAIC, percebemos que sua ênfase não está no processo de aprendizagem como nos demais programas analisados - PCN em Ação, PROFA, PRÓ-LETRAMENTO -, mas no resultado. Com isso não queremos dizer que o programa não apresente uma preocupação com o processo de alfabetização ou que os outros também não trabalhassem em prol dessa conquista, mas, que essa mudança de foco produziu novas práticas e ressignificou outras, pois, ao buscar os resultados das metas estabelecidas, amplia-se a rede de controle e vigilância.

Um resultado que depende de muito trabalho, dedicação, cuidado, atenção, carinho e investimentos dos governos, das escolas, professores, famílias e a mobilização vigilante de toda a sociedade [...] alfabetizar as crianças até, no máximo, os oito anos de idade, aferindo os resultados por exame periódico específico (BRASIL, 2012, p. 11)

Em 2013, o Ministério da Educação publicará um edital informando os critérios de premiação e reconhecimento aos professores, escolas e redes de ensino que mais avançarem na alfabetização das suas crianças, considerando os resultados aferidos nas avaliações (BRASIL, 2012, p. 13) 
Disponibilizar assistência técnica às escolas com maiores dificuldades na implementação das ações e na obtenção de resultados positivos de alfabetização [...] É fundamental que toda a sociedade se mobilize, ou seja, aja coletivamente com o objetivo de alcançar o resultado almejado, qual seja garantir que todas e cada uma das crianças brasileiras estejam alfabetizadas, no máximo, até os 8 anos de idade [...] garantir a plena alfabetização de nossas crianças. Alfabetizar todas as crianças, sem exceção, e no momento certo: até o final do terceiro ano do ensino fundamental, quando elas completam oito anos de idade [...] Agora é chegado o momento de realizar essa tarefa (BRASIL, 2012, p. 38 ).

Essa nova ênfase reforçou algumas práticas, ressignificou e institui outras, dentro de uma racionalidade neoliberal. Assim, o PNAIC através dos resultados da alfabetização, aferidos por avaliações, convida a todos a compreender a alfabetização escolar como a "grande verdade" - da qual não ousamos suspeitar - e a inclinar-se a ela - somos convocados a lutar para que se efetive.

Um resultado que depende de muito trabalho, dedicação, cuidado, atenção, carinho e investimentos dos governos, das escolas, professores, famílias e a mobilização vigilante de toda a sociedade (BRASIL, 2012, s/p).

É fundamental que toda a sociedade se mobilize, ou seja, aja coletivamente com o objetivo de alcançar o resultado almejado, qual seja garantir que todas e cada uma das crianças brasileiras estejam alfabetizadas, no máximo, até os 8 anos de idade (BRASIL, 2012, 39).

Comprometer-se com algo em comum implica num esforço para que as coisas funcionem da melhor forma possível. No âmbito institucional, a partir do PNAIC, houve um compromisso firmado entre os governos do Distrito Federal, dos estados dos municípios para assegurar que todas as crianças estejam alfabetizadas até os oito anos de idade (BRASIL, 2012), o que acarretou na corresponsabilização como princípio tático do programa de formação dos professores.

Nessa relação, vemos a ênfase desse compromisso colocada no professor, convocando-o para a responsabilização social em torno do "futuro de nosso país" (BRASIL, 2012, s/p) e a serviço do Estado.

As Ações do Pacto são um conjunto integrado de programas [...] tendo como eixo principal a formação continuada dos professores alfabetizadores [...] professor é uma figura central e determinante no processo de alfabetização (BRASIL, 2012, p. 11). 
Professores comprometidos e responsáveis precisam investir em si mesmos - para estarem "bem preparados" - e ter uma predisposição firme - estarem "motivados" - para assumirem o desafio de alfabetizar todas as crianças, por isso, se faz necessário a "inversión en acciones, en formación y la acreditación en el profesor de la responsabilidad por la cualidad de los sistemas, instituciones escolares y procesos de aprendizaje del alumnado" (POSSA, 2016, p. 77).

Dessa maneira, os professores são cada vez mais seduzidos por "uma atitude e uma cultura nas quais se sintam responsáveis e, ao mesmo tempo, de certa forma, pessoalmente investidos da responsabilidade" (BALL, 2005, p. 545) pelo sucesso na e da alfabetização.

Nessa perspectiva, o PNAIC ao abordar a aprendizagem como um "direito humano" (BRASIL, 2012b, p. 8) responsabiliza os professores pela inclusão e permanência dos alunos como sujeitos aprendentes dessa Sociedade de Aprendizagem (NOGUERA-RAMÍREZ, 2013), instituindo para o professor

[...] uma dupla responsabilidade. Ele é responsável por seu próprio estilo de vida e por criar um ambiente que propicie a aprendizagem, a segurança e a saúde de todos os envolvidos, inclusive de si mesmo. Todavia, essas imagens e narrativas do social e do indivíduo são também divisões que colocam alguns para fora de seu mapeamento cultural: não civilizados, bárbaros, outsiders, aquém e carentes de humanidade [...] (POPKEWITZ et al., 2009, p. 91).

No material analisado é possível ver isso em funcionamento:

O curso de formação abordará a inclusão de crianças com necessidades educacionais especiais [...] priorizando o atendimento das crianças do $1^{\circ}$, $2^{\circ}$ e $3^{\circ}$ ano do ensino fundamental como garantia de educação integral e complementação e apoio pedagógico àquelas com maiores dificuldades (BRASIL, 2012, p. 35).

Portanto, o curso tem enfoque sobre os planos de aula, as sequências didáticas e a avaliação diagnóstica, onde se faz um mapeamento das habilidades e competências de cada aluno, para traçar estratégias que permitam ao aluno aprender efetivamente (BRASIL, 2012, p. 24).

Considerando que a avaliação é parte constituinte do processo pedagógico e que, com base nela, é possível entender melhor quais são os conhecimentos 
das crianças e suas dificuldades, podem ser desenvolvidas estratégias diversas em sala de aula em que as crianças sejam atendidas de formas diferenciadas (BRASIL, 2012, p. 35).

Essas "estratégias diversas" configuram-se no gerenciamento de riscos através do monitoramento contínuo, permeado por atividades de "avaliações contínuas".

(...) destaca-se que o êxito do processo de alfabetização reside também na capacidade de acompanhar continuamente o progresso da aprendizagem das crianças, por meio de avaliações contínuas, que podem ser baseadas em observações e registros sistemáticos de cada criança, bem como por avaliações estruturadas, a exemplo da Provinha Brasil (BRASIL, 2012, p. 21).

O gerenciamento de riscos, através das "avaliações estruturadas", está vinculado a metas que passam a ordenar e regular medidas. Os resultados de alfabetização - produzidos pelos dados estatísticos - reconfiguram as políticas públicas, os sistemas educacionais, as instituições escolares, os processos de ensino e aprendizagem e o desempenho dos professores, conformando suas práticas para atingir as metas estabelecidas.

A terceira medida é a aplicação, junto aos alunos concluintes do $3^{\circ}$ ano, de uma avaliação externa universal, pelo INEP, visando aferir o nível de alfabetização alcançado ao final do ciclo, e que possibilitará às redes implementar medidas e políticas corretivas (BRASIL, 2012, p. 13).

O INEP aplicará uma avaliação universal no final do $3^{\circ}$ ano para aferir os resultados de todo o Ciclo de Alfabetização. Ela servirá para verificar se as crianças estão alfabetizadas e com condições de seguir seu fluxo escolar. Os dados serão disponibilizados logo no início do ano seguinte para elaboração de estratégias de prosseguimento do trabalho escolar (BRASIL, 2012, p. 34).

Uma avaliação externa universal é importante, pois não afere somente os resultados obtidos pelos estudantes, mas sim todo esforço empenhado pelos sistemas e redes de ensino para o cumprimento da meta (BRASIL, 2012, p. $34)$.

O Pacto Nacional pela Alfabetização na Idade Certa terá duas frentes de avaliação das crianças [...] Será aplicada também, no início e final do $2^{\circ}$ ano, 
a Provinha Brasil, com o objetivo de diagnosticar, por meio de instrumento sistematizado, quais conhecimentos sobre o sistema alfabético de escrita e quais habilidades de leitura as crianças dominam [...] No final do $3^{\circ}$ ano será aplicada, pelo Instituto Nacional de Estudos e Pesquisas Educacionais Anísio Teixeira (Inep), uma avaliação externa anual para checagem de todo o percurso de aprendizagem do aluno [...] Com base nos dados analisados por meio dos instrumentos de avaliação, os professores serão auxiliados na tarefa de planejar situações didáticas que favoreçam as aprendizagens (BRASIL, 2012, p. p. 13).

o Ministério da Educação publicará um edital informando os critérios de premiação e reconhecimento aos professores, escolas e redes de ensino que mais avançarem na alfabetização das suas crianças, considerando os resultados aferidos nas avaliações (BRASIL, 2012d p. 13).

Dessa forma, é possível perceber que formação continuada do PNAIC se movimenta numa lógica performática em que o professor possa incorporar para si, tanto a avaliação de larga escola como resultado de seu trabalho, para consumir modelos e práticas narradas como melhores e para inserirem-se como indicador de desenvolvimento econômico e social. As estatísticas são produzidas no conjunto de uma tecnologia política de governamentalidade que é projetada por uma cultura performativa para os modos de vida neoliberais que são detalhados nos indicadores.

Ball (2014) tem se dedicado a estudar os efeitos da performatividade na educação, em especial nos processos de subjetivação dos professores. Segundo o referido autor, a cultura da performatividade é um mecanismo chave porque desenvolve uma tecnologia política como forma e meio de governar: processos de medidas e comparação que organizam as condições para governar. No caso da formação do professor alfabetizador, a possibilidade de ele mesmo produzirse pelo governo, mas também ser o empreendedor que se empodera de governar a infância nos processos de alfabetização.

A performatividade para Ball (2014) é uma forma de se referir ao sistema de desempenho, mas, sobretudo, uma atuação, na qual os resultados da medição do desempenho passam a ter nas subjetividades, nas práticas institucionais, na economia e no governo, através de políticas globais que se desdobram localmente e nos indivíduos.

[...] a performatividade desempenha papel crucial no conjunto das políticas educacionais contemporâneas. Contribui para integrar e redimensionar atividades, processos e resultados. Facilita o monitoramento do Estado e 
propicia sua intromissão nas culturas, práticas e subjetividades das instituições educativas e de seus profissionais. Altera os significados, produz novos perfis e garante o alinhamento. Transforma o processo de ensinar e de apreender o conhecimento em objeto e em mercadoria, limitando-o a produtos, a níveis de desempenho e a padrões de qualidade [...] (MOREIRA, 2009, p. 33-34).

O PNAIC, com a devida proporção dentre todas as políticas e programas implementados, tem se constituído, como um dos modos de produção de subjetividades docentes para que estes estejam performaticamente emparelhados com as metas indicadas, buscando resolver nos contextos da atuação docente - com eficiência - a aplicação de soluções para os baixos índices e resultados que produzem riscos no desenvolvimento social e econômico.

Considerando que a avaliação é parte constituinte do processo pedagógico e que, com base nela, é possível entender melhor quais são os conhecimentos das crianças e suas dificuldades, podem ser desenvolvidas estratégias diversas em sala de aula em que as crianças sejam atendidas de formas diferenciadas [...] lançar mão de estratégias de acompanhamento especial às crianças que, em relação aos objetivos esperados, estejam precisando de apoio pedagógico mais intenso e diferenciado (BRASIL, 2012, p. 35).

A Tese "Performatividade e inclusão no movimento Todos pela Educação" (HATTGE, 2014), que articula a performatividade aos conceitos de inclusão e aprendizagem, também corroborou na produtividade da performatividade na educação, principalmente, aos seus efeitos vinculados ao programa PNAIC.

Segundo Hattge (2014), a transformação da aprendizagem em um direito, possibilitou que ela fosse transmutada em desempenho, no qual, pode ser medido. Isso torna possível o monitoramento da "garantia" desse direito. A autora, discute que esse movimento - a aprendizagem transformada em direito - permitiu que a performatividade pudesse operar. O programa PNAIC, sendo uma política instituída a partir do direito à aprendizagem, emerge dentro dessa lógica performática.

É possível perceber que essa lógica performática, além de estar presente nas avaliações de larga escala inseridas - Provinha Brasil - e propostas pelo programa - Avaliação Nacional da Alfabetização (ANA) - perpassa as principais atividades desenvolvidas na formação continuada, através dos diagnósticos individuais dos alunos, relatórios e do preenchimento de tabelas de 
acompanhamento que são transformados, pelos professores, em dados numéricos para serem inseridos no sistema $\mathrm{SISPACTO}^{4}$ e monitorados.

Ao pensar nas práticas de formação do PNAIC, inseridas numa lógica performática, procuramos visualizar a sua produtividade na produção do professor alfabetizador. Percebemos que o PNAIC, ao "dispor as coisas" (FOUCAULT, 2012, p. 284) - metas, quadros de acompanhamento, sistemas de monitoramento, resultados de avaliações externas, premiações -, conduz as condutas docentes a estágios elevados de desempenho (SILVA, 2011), se propondo a qualificar as performances dos professores nas tramas da racionalidade neoliberal.

Ao ir preenchendo os quadros, registrando dados e inserindo informações no sistema, o professor vai se narrando, se vendo, se julgando, de modo a ir se produzindo segundo uma intrincada combinação entre aquilo que ele conseguiu fazer, aquilo que ele deve fazer, aquilo que ele espera que os outros pensem e vejam que ele é capaz de fazer. Acreditamos que esse processo produz no professor uma vontade de competir: uma competição não só com os outros, mas principalmente, consigo mesmo.

No texto "Governamentalidade e educação", Veiga Neto (2013), ao problematizar as possíveis articulações entre a governamentalidade neoliberal e a educação, apresenta outros elementos que julgo interessante para pensar as práticas da produção do professor no programa de formação continuada PNAIC.

Segundo o autor, no neoliberalismo a liberdade precisa ser continuamente produzida e exercitada sob a forma de competição e esse princípio vai fazer com que a escola seja uma instituição de maior interesse para o sistema neoliberal:

[...] a governamentalidade neoliberal intervirá para maximizar a competição, para produzir liberdade para que todos possam estar no jogo econômico [através de] processos [...] continuamente ensinados, governados, regulados, dirigidos, controlados [...] (VEIGA NETO, 2013, s/p).

Assim, se torna mais "produtivo e pertinente compreender o neoliberalismo como formas de vidas [...] como maneiras de ser e de estar no mundo" (VEIGA-NETO, 2013, s/p). E isto, tem uma grande importância para a escola, pois ela deixa de ser vista como "um lugar onde se

4 O SISPACTO é o sistema de monitoramento do Pacto Nacional pela Alfabetização na Idade Certa disponibilizado no SIMEC (http://simec.mec.gov.br). Os participantes, envolvidos na execução das ações do Pacto, têm acesso ao SisPacto. Disponível em http://pacto.mec.gov.br/31-outros-destaques/79-entenda-o-sispacto. Acesso em 20 ago. 2017. 
ensinam e se aprendem ideologias [para] ser entendida como uma instituição encarregada de fabricar novas subjetividades" (Idem, idem) que atendam as demandas neoliberais.

Além da competição e da liberdade, na fabricação de novas subjetividades, outro elemento interessante abordado no texto foi a questão da inovação, vinculada ao deslocamento da centralidade da fábrica para a empresa.

Segundo Veiga Neto (2013), a fábrica era uma instituição com uma presença espacial marcante, pertencente a uma economia baseada em máquinas e em prédios, com um trabalho especializado e uma rotina definida, onde o que importava era o corpo do trabalhador - "o trabalho fabril era um trabalho com um recorte bem definido no tempo e no espaço: acontecia integralmente no ambiente da fábrica e dentro da jornada de trabalho" (VEIGA NETO, 2013, s/p).

Já a empresa é uma instituição flutuante no ciberespaço, pois se desloca dos locais onde se situa e cria lugares voláteis, dispondo de equipamentos digitais em conjuntos comerciais, com número de trabalhadores reduzido e o regime de trabalho bastante heterogêneo - cada um constitui-se em um caso particular, com uma forma de contrato, carga horária e funções diferenciadas - que já não está mais limitado ao espaço da empresa, nem à jornada de trabalho, pois agora a prioridade não é mais "o corpo [do trabalhador] e seus movimentos mecânicos, mas a alma ${ }^{5}$ e o seu poder criativo" (VEIGA-NETO, 2013, s/p).

Nesse sentido, a inovação se torna o centro do processo, pois, na empresa o foco não está na produção e reprodução de artigos manufaturados, mas "na criação de novos mundos" (VEIGANETO, 2013, s/p). Portanto, o trabalho não é realizado por um sujeito altamente especializado, mas sim, por um sujeito flexível, dotado de poder de gestão das informações e de tomada de decisões.

Assim, fica mais do que evidente o quanto tudo isso tem a ver com a necessidade da produção de um professor que, além de estar inserido nessas práticas, possa ser produtivo, conduzindo as condutas das crianças, nos processos de alfabetização, para que exerçam o empresariamento de si mesmas.

No neoliberalismo - e ele não esconde, ele proclama isso —, também vai se encontrar uma teoria do homo oeconomicus, mas o homo oeconomicus, aqui,

5 As práticas de confinamento analisadas anteriormente mostram que não estão restritas ao espaço físico, mas às atividades de experiências executadas pelos professores. Elas fazem parte de tarefas cotidianas e subjetivam um modo de fazer e atuar como alfabetizador, por isso se aderem a alma, o que explica o governo das condutas flexíveis. 
não é em absoluto um parceiro da troca. O homo oeconomicus é um empresário, e um empresário de si mesmo. Essa coisa é tão verdadeira que, praticamente, o objeto de todas as análises que fazem os neoliberais será substituir, a cada instante, o homo oeconomicus parceiro da troca por um homo oeconomicus empresário de si mesmo, sendo ele próprio seu capital, sendo para si mesmo seu produtor, sendo para si mesmo a fonte de [sua] renda (FOUCAULT, 2008b, p. 310-311).

Ao olhar para as práticas da produção do professor alfabetizador na formação continuada do PNAIC, percebemos "como a economia de mercado organiza e regula o Estado, especialmente, os processos de educação e escolarização" (HERMES, 2012, p. 16).

\section{Considerações Finais}

A análise e discussão dos dados da Dissertação de Mestrado em Políticas Públicas e Gestão Educacional, neste trabalho, possibilitaram mostrar a produção do professor alfabetizador na formação continuada do PNAIC, no contexto da racionalidade neoliberal. A racionalidade neoliberal inscreve o empresariamento de si mesmo na docência, operando na produção de práticas que levam o professor a inserir-se em uma lógica performática, a partir da competição com os outros e consigo mesmo. Assim, a produção de um professor 'apropriado' para a alfabetização - o professor alfabetizador - produz uma forma de condução em que todos e cada um deve investir em si mesmo, a fim de garantir o sucesso da alfabetização.

Pensando nessas práticas como produtoras do professor alfabetizador, percebemos que a vontade de competir produz um professor responsável, comprometido com o sucesso de si próprio, dos outros e do Estado. O professor torna-se alguém empenhado no cumprimento das metas e para isso, investe em si, em suas capacidades e busca empregar as estratégias mais adequadas, garantindo para si as condições necessárias para cumprir tal tarefa. A vontade de competir fabricada nas práticas do PNAIC como prática performática - demarcam a produção desse professor na racionalidade neoliberal: um professor economicamente produtivo e politicamente útil. 


\section{REFERÊNCIAS}

BALL, S. J. Profissionalismo, gerencialismo e performatividade. Cadernos de Pesquisa, São Paulo, v. 35, n. 126, p. 539-564, set./dez., 2005.

sa: UEPG, 2014.

Educação Global S.A.: novas redes políticas e o imaginário neoliberal. Ponta Gros-

BRASIL. Parâmetros Curriculares Nacionais: introdução aos parâmetros curriculares nacionais. Secretaria de Educação Fundamental. Brasília, 1997a.

Parâmetros Curriculares Nacionais: língua portuguesa. Secretaria de Educação Fundamental. Brasília, 1997b Brasília, 1999a.

Referenciais para a Formação de Professores. Secretaria de Educação Fundamental.

Programa de desenvolvimento profissional continuado: alfabetização. PCN em Ação. Secretaria de Educação Fundamental. Brasília, 1999b.

Orientações Gerais. Objetivos, diretrizes e funcionamento. Rede Nacional de Formação Continuada de Professores de Educação Básica. Centros de Pesquisa e Desenvolvimento da Educação. Ministério da Educação, 2005.

. Manual do Pacto Brasília: Ministério da Educação, 2012.

. Elementos Conceituais e Metodológicos para Definição dos Direitos de Aprendizagem e Desenvolvimento do Ciclo de Alfabetização ( $\left(1^{\circ}, 2^{\circ}\right.$ e $3^{\circ}$ anos) do Ensino Fundamental. Brasília: Ministério da Educação, 2012b.

BUJES, M. I. Descaminhos. In: COSTA, Marisa V. (org.) Caminhos investigativos: outros modos de pensar e fazer pesquisa em educação. 2. ed. Rio de Janeiro: Lamparina, 2007, p.13-34.

COUTINHO, K.; SOMMER, L. H. Discursos de sobre Formação de Professores. In: Currículo Sem Fronteiras. v.11, n.1, p.86-103, Jan/Jun 2011.

DELORS, J. Educação: um tesouro a descobrir. Relatório para a UNESCO da Comissão Internacional sobre Educação para o século XXI. 6 ed. São Paulo: Cortez; Brasília, DF: MEC/ UNESCO, 2001.

DIAS, K. de A. A formação continuada dos profissionais da educação da rede municipal de 
Florianópolis: governamento e constituição de subjetividades docentes. 2017. 305p. Tese (Doutorado). Universidade Federal de Santa Catarina, Centro de Ciências da Educação, Programa de Pós-Graduação em Educação, SC, 2017.

FOUCAULT, M. A arqueologia do saber. Rio de Janeiro: Forense Universitária, 1995.

Do Governo dos Vivos: curso no Collège de France 1979- 1980: Excertos. SP/RJ: Achiamé, 1997.

Segurança, Território, População. São Paulo: Martins Fontes, 2008.

Microfísica do Poder. Organização e tradução de Roberto Machado. Rio de Janeiro:

Edições Graal, 2012a.

HATTGE, M. D. Performatividade e inclusão no movimento todos pela educação. 2014. p.186. Tese (Doutorado). Universidade do Vale do Rio do Sinos, Programa de Pós-Graduação em Educação, São Leopoldo, RS, 2014.

LOCKMANN, K. A proliferação das políticas de assistência social na educação escolarizada. 2013. p. 317. Tese (Doutorado em Educação), Programa de Pós-Graduação em Educação da Universidade Federal do Rio Grande do Sul, Porto Alegre, RS, 2013.

MACHADO, R. B. A inclusão como rede: uma análise de práticas de professores de Educação Física na Contemporaneidade. 2016. p. 309. Tese (Doutorado em Educação), Programa de Pós-Graduação em Educação da Universidade Federal do Rio Grande do Sul, Porto Alegre, RS, 2016.

MILLER, P; ROSE, N. Governando o presente: gerenciamento da vida econômica, social e pessoal. Trad. Paulo Ferreira Valério. SP: Paulus, 2012.

MOREIRA, A. F. A cultura da performatividade e a avaliação da pós-graduação em educação no Brasil. Educação em Revista, Belo Horizonte, v. 35, n. 3, p. 23-42, dez. 2009.

NOGUERA-RAMIREZ, C. A governamentalidade nos cursos do professor Foucault. In: BRANCO, G.; VEIGA-NETO, A. (Orgs.). Foucault, filosofia e política: BH: Autêntica, 2013.

POPKEWITZ, T. S.; OLSSON, Ulf; PETERSSON, K. Sociedade da Aprendizagem, Cosmopolitismo, Saúde Pública e Prevenção à Criminalidade. Educação e Realidade, Porto Alegre (RS), n. 34, p. 73-96, mai/ago 2009.

POSSA, L. B. La formación del profesor de la Educación Especial en Brasil e España. In: SE- 
NENT, J. M.; LAZÁRO, L. M. (eds.). Jacarandá: escritos de Educación Comparada e Internacional. Valencia: Servei de Publicaciones de la Universidad de Valencia, 2016, p. 77-101.

ROSE. N. Inventando nossos selfs: Psicologia, poder e subjetividade. Petrópolis: Vozes, 2011.

SILVA, R. R. D. A constituição da docência no Ensino Médio no Brasil contemporâneo: uma analítica de governo. 2011. 215 p. Tese (Doutorado). Universidade do Vale do Rio dos Sinos, Programa de Pós-Graduação em Educação, São Leopoldo, RS, 2011.

TRAVERSINI, C. S. Debite um analfabeto no seu cartão: a solidariedade como estratégia para alfabetizar a população e desresponsabilizar o Estado. In: Educação em Revista, Belo Horizonte, MG, v.43, p.73-93, jun. 2006.

UNESCO. Declaração Mundial sobre Educação para Todos: satisfação das necessidades básicas de aprendizagem. Jomtien, 1990. Disponível em: <http://unesdoc. unesco.org/ images/0008/000862/086291 por.pdf>. Acesso em: 12 jan. 2017.

Educação para Todos: o compromisso de Dakar. Brasília: UNESCO, CONSED. Ação Educativa: Brasília, 2001. Disponível em: <http://unesdoc.unesco.org/ images/0012/001275/127509porb.pdf>. Acesso em: 12 jan. 2017.

VEIGA-NETO, A. A ordem das disciplinas. 1996. 344p. Tese (Doutorado). Universidade Federal do Rio Grande do Sul, Faculdade de Educação, Programa de Pós-Graduação em Educação, RS, 1996.

Governamentalidade e educação. In: Revista Colombiana de Educación, n ${ }^{\circ} 65$ Bogotá July/Dec. 2013a. Disponível em <http://www.scielo.org.co/scielo.php?script=sci_arttext\&p $\mathrm{id}=\mathrm{S} 0120-39162013000200002>$. Acesso em 10 ago. 2017. 